\title{
Biologically mediated sediment fluxes on coral reefs: sediment removal and off-reef transportation by the surgeonfish Ctenochaetus striatus
}

\author{
Christopher H. R. Goatley*, David R. Bellwood \\ Australian Research Council Centre of Excellence for Coral Reef Studies and School of Marine and Tropical Biology, \\ James Cook University, Townsville, Queensland 4811, Australia
}

\begin{abstract}
Off-reef sediment transport by the surgeonfish Ctenochaetus striatus (Acanthuridae) was quantified on the reef crest at Lizard Island, Great Barrier Reef. Three independent methods were implemented to estimate sediment ingestion rates. These considered (1) the bite rate and bite volume, (2) the defecation rate and faecal pellet size, and (3) the average gut contents and throughput rate. The 3 methods provided a broad range of estimates of sediment ingestion from $8.8 \pm 2.4$, to $66.1 \pm 14.4 \mathrm{~g} \mathrm{fish}^{-1} \mathrm{~d}^{-1}$ (mean $\pm \mathrm{SE}$ ). Nevertheless, these estimates were comparable to rates of sediment ingestion by parrotfishes (Labridae), the other major sediment-moving group on reefs. Overall, $36.5 \%$ of all sediment ingested was transported from the upper reef crest into deeper water, equating to a removal rate of $28.6 \pm 6.2 \mathrm{~kg} 100 \mathrm{~m}^{-2} \mathrm{yr}^{-1}$ at the study site. By brushing the reef, C. striatus reduces the sediment loading in the epilithic algal matrix (EAM) while causing little damage to the algal turf. Reducing sediments in EAMs provides favourable settlement surfaces for benthic organisms and increases the palatability of the EAM to herbivorous reef fishes, thus supporting reef resilience. The ecological importance of $C$. striatus, which is abundant on reefs throughout the IndoPacific, appears to have been underestimated, particularly when considering reef sediment dynamics.
\end{abstract}

KEY WORDS: Ctenochaetus striatus $\cdot$ Sediment transport $\cdot$ Coral reef $\cdot$ Reef fish

Resale or republication not permitted without written consent of the publisher

\section{INTRODUCTION}

The ecological impacts of sediments on coral reefs are of considerable importance to reef resilience and development over almost all spatial and temporal scales. Impacts of altered sedimentation can be noted in individual organisms in a matter of hours or days (Rogers 1983, Fabricius et al. 2007, Bellwood \& Fulton 2008), whilst longer term changes in sedimentation patterns can control the development of entire reef systems over geological time (Blanchon \& Shaw 1995, Airoldi 2003, Perry et al. 2008). Some effects of sedimentation seem beneficial (Adams et al. 2009); however, the majority are deleterious. The negative effects of increased sediment loads range from altered feeding patterns in corals and fishes (Anthony \& Fabricius 2000, Bellwood \& Fulton 2008) to reduced reef accretion rates during times of sea level rise, ultimately leading to the drowning of entire reefs (Blanchon \& Shaw 1995).

Many studies of marine sedimentation have focussed on changing coastal land-use patterns and the effects of associated increases in terrigenous sediment output (e.g. Neil et al. 2002, McCulloch et al. 2003, Fabricius 2005). Factors affecting sedimentation on reefs less impacted by coastal inputs, such as oceanic reefs or those in mid- or outer-shelf regions (Larcombe \& Woolfe 1999), have been the subjects of less investigation.

Studies considering sedimentation on these more isolated reefs have traditionally been made from either a physiological or a geological approach, the former considering the effects of sediment on reef biota and the latter studying the physical processes involved in the production, taphonomy (the breakdown of biogenic structures) and eventual fates of reef sediments. Few studies have provided information to link the 2 
disciplines at an ecological scale. Nevertheless, ecological studies are vital as they help to identify the mechanisms that bestow coral reef resilience at a scale at which changes can be both detected and managed (e.g. Airoldi 2003, Bellwood et al. 2004, Airoldi et al. 2008, Bellwood \& Fulton 2008).

At an ecological scale, studies of sea urchins (Echinoidea) and parrotfishes (Labridae) have proved to be the most illuminating, and their roles in bioerosion (Bellwood 1995a, Bruggemann et al. 1996, CarreiroSilva \& McClanahan 2001) and taphonomy (Lipps 1988, Scoffin 1992, Bellwood 1996) are now routinely incorporated in 'more geological' models (e.g. Scoffin 1992, Bak 1994, Mallela \& Perry 2007). Parrotfishes also influence sediment resuspension (Yahel et al. 2002) and transport (Bellwood 1995b) on reefs, and, as these processes have yet to be incorporated into reef carbonate budgets, they represent an unconsidered mechanism of biologically mediated sediment flux on coral reefs.

While the previously mentioned studies provide a useful starting point, to date, the study of biologically mediated sediment flux by fishes on coral reefs has been limited to that of parrotfishes. Some members of this taxon defecate away from their feeding areas, in deeper water, thus transporting sediment off reefs in the process (Bellwood 1996). While parrotfishes might be the most important group involved in biologically mediated sediment flux, many other fish taxa feed on constituents of sediment-laden epilithic algal matrices (EAMs), and, whether these fish are targeting detritus, infaunal organisms or the turfs themselves, some sediment is likely to be ingested as they feed. The impact of these fishes on reef sediment dynamics is currently unknown.

Of the fishes feeding on Indo-Pacific EAMs, the lined bristletooth surgeonfish Ctenochaetus striatus (Acanthuridae) stands as one of the most likely candidates for being important in biological sediment flux. These fish are abundant on most Indo-Pacific coral reefs and are frequently the most abundant large, roving herbivore/detritivore (Choat \& Bellwood 1985, Trip et al. 2008). They have relatively high feeding and gut throughput rates (Polunin et al. 1995, Choat et al. 2004) and a diet that is comprised of fine particulates including sediment (Choat \& Bellwood 1985, Choat 1991), which is removed using highly modified brush-like teeth (Purcell \& Bellwood 1993). Furthermore, C. striatus defecate away from their primary feeding surface and often repeatedly defecate in the same location, transporting sediment away from their feeding surfaces in the process (Bellwood 1995b, Krone et al. 2008). To assess the potential importance of this species in biologically mediated sediment flux on IndoPacific coral reefs, the present study has quantified the amount and direction of sediment transported by $C$. striatus on a mid-shelf reef on the Great Barrier Reef, Australia.

\section{MATERIALS AND METHODS}

Study location. Research was conducted at Lizard Island in the northern section of the Great Barrier Reef (GBR). Two sites (A and B) were chosen along the fringing reef to the south of the island. The sites are at an oblique angle to the prevailing south-easterly winds in the region, leading to moderate hydrodynamic exposure. As Ctenochaetus striatus are most abundant on reef crests, this zone was the focus of the present study at both sites. Within the reef crest, 3 habitats upper, mid and lower-were considered, to assess how $C$. striatus drives sediment fluxes within the reef crest. These habitats were clearly defined: the upper consisted of a primarily horizontal reef matrix from 0.5 to $2 \mathrm{~m}$ deep; the mid, a sloping region to from 2 to $4 \mathrm{~m}$ deep; and the lower, a primarily horizontal, rubbledominated surface from 4 to $6 \mathrm{~m}$ deep.

Sediment ingestion by Ctenochaetus striatus. Initially the amount of sediment removed from the reef crest by C. striatus was estimated using the 3 methods described in the following. Subsequently, the results were compared to consider the reliability of the methods used. The most reliable method was then used to calculate sediment transport and the overall importance of $C$. striatus in sediment transport on coral reefs.

Bite rates and bite volume: The first method used to estimate sediment uptake by Ctenochaetus striatus was a video-based focal animal approach. To randomise the selection of fishes, the first fish seen after a 1 min timed swim was selected. To simplify analyses, only the most abundant size class of fish $(200 \pm 50 \mathrm{~mm}$ total length; mean \pm SE) was selected. This omitted only a few small individuals. The activities of the fish were recorded for 5 to $10 \mathrm{~min}$ using an underwater video camera. Over both sites, a total of 170 videos were recorded over $13 \mathrm{~d}$. All videos were viewed in slow motion to accurately count the number of bites the fish made on the benthos, then again at full speed to time how long the fish was visible in the frame, allowing an accurate calculation of bite rate to be made. To test the efficacy of the method, 10 of the videos were recorded while a second observer counted bite rates of the same fish in situ. All videos and observations were undertaken prior to collections. The videos were used for 3 purposes.

First, 65 videos were recorded during the day (10:00 to $16: 00 \mathrm{~h}$ ) to estimate a bite rate over most of the feeding day for Ctenochaetus striatus. Second, to measure the length of the feeding day, 18 videos were recorded just prior to sunset (17:11 to $18: 31 \mathrm{~h})$. This allowed any 
reduction in bite rate and the cessation of feeding to be determined. Finally, a further 87 videos were recorded from sunrise until the first defecation was observed (06:12 to 09:33 h). A regression of mean bite rate over time (standardised to minutes after sunrise) allowed the number of bites made at any time prior to first defecation to be estimated. This increased the accuracy of the estimate of the total number of bites made per day by $C$. striatus and enabled an estimate of the size of each bite to be made using the gut contents of fish collected prior to first defecation.

To estimate the size of each bite, 3 fish were collected using spears prior to commencement of feeding, and 11 fish were collected after first feeding but before first defecation. The time that each fish was collected was noted. The gut contents were removed and bleached using $10 \%$ sodium hypochlorite solution (following Bellwood 1996) to remove all organic materials, leaving just the ingested sediments. Following bleaching and rinsing, the samples were dried to constant weight at $40^{\circ} \mathrm{C}$ and weighed. The time that the fish was collected was then plotted on the bite rate increase regression (above) to estimate the number of bites taken. The mass of sediment in the guts was divided by the number of bites to provide an estimate of the mass of sediment ingested per bite. The 3 fish collected prior to first feeding were used to correct for the trace amount of sediment that remained in the gut from the previous day's feeding. The number of bites made by Ctenochaetus striatus each day was multiplied by the mass of sediment ingested per bite to provide the first estimate of daily sediment ingestion. For this and all subsequent methods, compound variances were calculated, where necessary, using a 2-term Goodman's estimator following Marnane \& Bellwood (2002).

Defecation rate and faecal pellet size: The second method used to estimate sediment transport by Ctenochaetus striatus considered the mean defecation rates and faecal pellet sizes. The defecation rate was derived from the 65 videos recorded during the day, and the mean mass of faecal pellets was calculated from 30 pellets collected in situ. To collect the faecal pellets, fish were followed using SCUBA until they were seen to defecate. Intact pellets were collected from the reef surface, stored in zip-lock bags, then bleached, rinsed and dried following the protocol outlined above; any pellet that could not be collected intact was rejected. The mean mass of sediment produced per minute was then multiplied by the number of minutes between the first observed defecation and sunset to provide the second estimate of sediment ingestion by C. striatus.

Gut contents and throughput rate: Twenty-two Ctenochaetus striatus from the most abundant size class $(200 \pm 50 \mathrm{~mm}$ standard length) were collected, using spears, from the study sites at Lizard Island in the early afternoon. The gut contents were removed and bleached as above. The gut contents were weighed, and the mean gut sediment content was calculated. Multiplying the mean mass of sediment from full guts by the estimated gut throughput rates of C. striatus (Polunin et al. 1995; $5.5 \mathrm{~d}^{-1}$ ) provided the third estimate of daily sediment ingestion.

Sediment transport by Ctenochaetus striatus. The 65 videos recorded during the day were reanalysed, recording the location of the first bite of any C. striatus. Using just the first viewed bite of each fish removes any issues of non-independence in the analysis, as every bite used was made by a different individual. The same method was used to assess defecations. The proportion of bites and defecations among the 3 reef crest habitats was then calculated to reveal patterns of sediment transport. These data, combined with the daily bite rate and bite volume estimates, were used to calculate the sediment transported per fish per day $\left(g\right.$ fish $\left.^{-1} \mathrm{~d}^{-1}\right)$.

The abundance of Ctenochaetus striatus at the study sites was determined from underwater visual censuses along the crest at Sites A and B $(50 \times 4 \mathrm{~m}$ belt transects, $\mathrm{n}_{\text {total }}=14$ ), following the pre-set distance method of Fulton et al. (2001).

Benthic sediments were collected from the crest habitats using an electric vacuum sampler and subsequently bleached and weighed (following Bellwood 1996, Purcell 1996). Sediments were collected from 10 replicate $5.8 \times 10^{-3} \mathrm{~m}^{2}$ rings at each crest habitat at each site. When combined with the daily bite rate and bite volume estimates, these data provided estimates of total sediment flux mediated by the populations of Ctenochaetus striatus at the study sites. The potential clearance rate of sediment from the habitats driven by C. striatus was also estimated.

\section{RESULTS}

To validate the methods used in the present study, data collected from video-based focal animal surveys were compared to those collected in situ by a diver. The video-based approach revealed a considerably higher bite rate than the diver-based bite rate estimation ( $t$-test: $t_{9}=5.16, \mathrm{p}<0.001$ ) with rates of $16.8 \pm 2.7$ bites $\mathrm{min}^{-1}$ versus $8.5 \pm 1.5$ bites $\min ^{-1}$ (mean $\pm \mathrm{SE}$ ), respectively. The video-based approach also allowed fishes to be followed for longer periods, as divers commonly lost track of fish when they paused to record data. For these reasons, all observation data for the present study were collected using video-based approaches. All values presented are as means $\pm \mathrm{SE}$, or, where necessary, means \pm Goodman's estimator of compound variance. 


\section{Sediment ingestion by Ctenochaetus striatus}

Bite rates and bite volume

Initially the number of bites made by an individual Ctenochaetus striatus per day was estimated. The average day length at Lizard Island is $728 \mathrm{~min}$. Three sections of the feeding day were considered: (1) the commencement of feeding until first defecation, (2) the main part of the feeding day, and (3) the cessation of feeding.

To calculate the number of bites made before the first defecation, a regression of mean bite rates per 10 min interval was made from the videos recorded from sunrise to the time of first defecation $(y=0.14 x-$ 10.96, $\mathrm{r}^{2}=0.76$; Fig. 1). This revealed that, on average, Ctenochaetus striatus make 933 bites prior to defecation, which occurs approximately 192 min after sunrise (09:33 h during the study).

Following first defecation, the average bite rate of Ctenochaetus striatus was calculated using the videos recorded throughout the day. Bite rates during the day were found to differ between the sites $\left(t_{63}=2.72, \mathrm{p}<\right.$ $0.01)$. Fish at Site A showed bite rates of $15.4 \pm 1.4$ bites min $^{-1}$ compared to $21.2 \pm 1.6$ bites $\min ^{-1}$ at Site B. In the 536 min between first defecation and sunset, individual C. striatus made $8275.8 \pm 745.0$ bites at Site A and $11379.3 \pm 830.8$ bites at Site B.

Feeding rates did not decline towards the end of the day (Fig. 2). Instead, fish were observed to cease feeding abruptly at dusk and to seek refuge in crevices in the reef. For this reason, the end of the feeding day was considered as sunset. Using the data above, an average of the total number of bites made by individual Ctenochaetus striatus was calculated. The mean

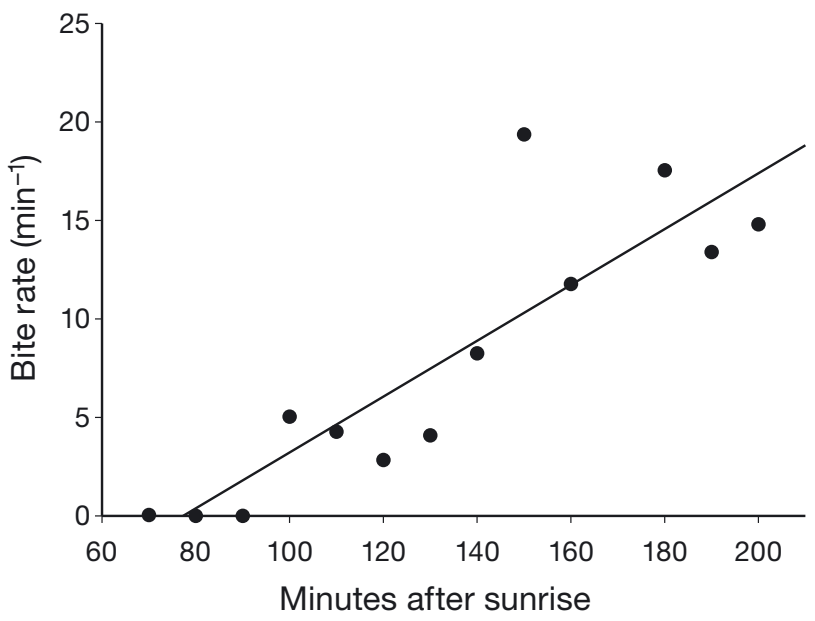

Fig. 1. Ctenochaetus striatus. Regression of mean bite rates per 10 min interval, standardised to minutes after sunrise $\left(y=0.1418 x-10.959, r^{2}=0.76\right)$ values were found to be $9208.8 \pm 745.0$ and $12312.3 \pm$

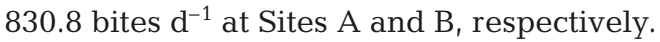

The mass of sediment ingested per bite by Ctenochaetus striatus was estimated. Prior to feeding, the mean residual sediment in the gut was found to be $0.19 \pm 0.02 \mathrm{~g}$. The number of bites made by each fish was calculated using the regression of feeding rate increase from sunrise (see 'Materials and methods: Bite rates and bite volume'). After correcting for residual gut sediments, the mass of sediment contained in the guts of the 11 fish collected prior to their first defecation was divided by the number of bites made, resulting in a mean mass of sediment ingested per bite of 1.0 $\pm 0.3 \mathrm{mg}$. Thus, the mean mass of sediment ingested by each fish was estimated to be $8.8 \pm 2.4$ and $11.8 \pm 3.3 \mathrm{~g}$ $\mathrm{d}^{-1}$ at Sites $A$ and $B$, respectively, using the first method (Fig. 3).

\section{Defecation rate and faecal pellet size}

The average number of defecations made per day by Ctenochaetus striatus was calculated from the video data. This revealed defecation rates of $0.19 \pm 0.04$ and $0.07 \pm 0.02 \mathrm{~min}^{-1}$ for Sites A and B, respectively. Using the time between sunrise and first defecation and the mean day length at Lizard Island, the length of a 'defecation day' was calculated to be 536 min. C. striatus therefore defecated on average $101.1 \pm 19.8$ and $37.7 \pm$ 10.3 times $\mathrm{d}^{-1}$ at Sites A and B, respectively.

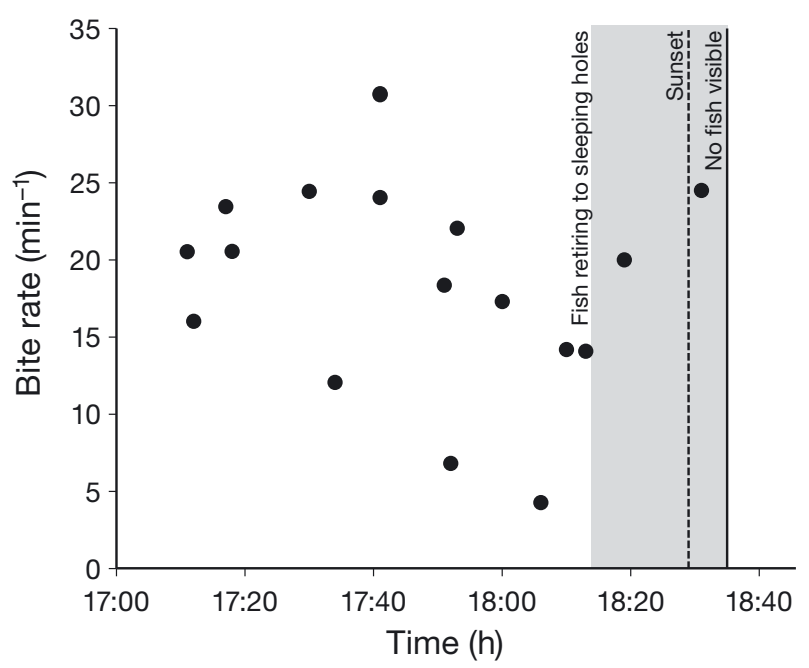

Fig 2. Ctenochaetus striatus. Feeding rates at the end of the feeding day. Each point is the bite rate determined from a single fish observed on video for a minimum of $5 \mathrm{~min}$. Linear regression was not significant. Grey: time over which fish abundances were observed to decline (fish retired to sleeping holes); dashed line: sunset on the sampling day; solid line: point after which no fish were visible on the reef (all retired to sleeping holes) 


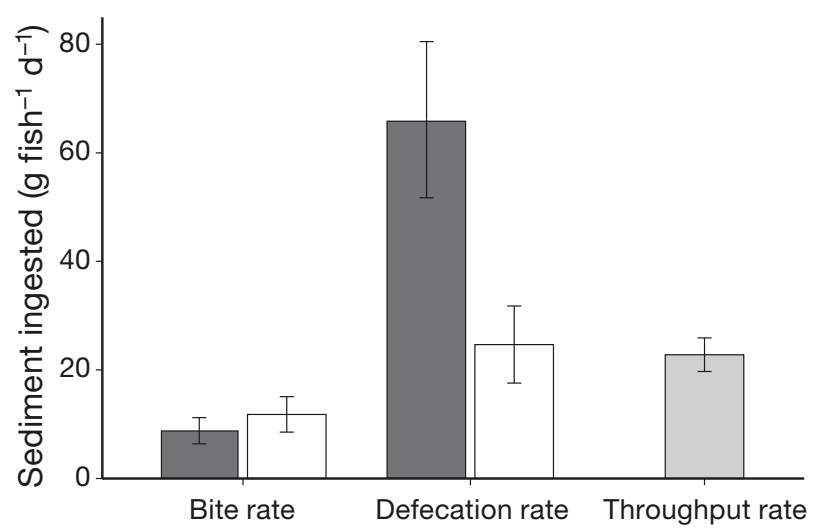

Fig. 3. Ctenochaetus striatus. Estimated mass of sediment ingested per day using the 3 methods: (1) bite rate and bite volume, (2) defecation rate and faecal pellet size and (3) average gut contents and throughput rate. Dark grey bars: Site $A_{;}$ open bars: Site B. Model 3 is represented by specimens collected from both sites (sites did not differ significantly), to minimise the number of fish collected at either

The mean mass of sediment in a faecal pellet was calculated from the 30 collected pellets and multiplied by the number of defecations made per day. No difference in the mass of sediment per pellet was found between the sites, so the data were pooled. Each pellet contained $0.7 \pm 0.1 \mathrm{~g}$ of sediments, resulting in an estimated sediment ingestion by Ctenochaetus striatus of $66.1 \pm 14.4$ and $24.7 \pm 7.1 \mathrm{~g} \mathrm{~d}^{-1}$ at Sites A and B, respectively, using the second method (Fig. 3).

\section{Gut contents and throughput rate}

The mean volume of sediment found in the guts of the 22 Ctenochaetus striatus collected during the day was $4.2 \pm 0.6 \mathrm{~g}$ (sites were not significantly different). Using published gut throughput rates (5.5 times $\mathrm{d}^{-1}$ ) this produced an estimated sediment removal rate of $22.8 \pm 3.1 \mathrm{~g} \mathrm{~d}^{-1}$ by each C. striatus (Fig. 3).

\section{Sediment transport by Ctenochaetus striatus}

Bites were predominantly taken from the upper reef crest $(45.9 \%)$, while defecations occurred most frequently at the lower reef crest $(45.0 \%$; Fig. $4 \mathrm{~A})$, with $79.6 \%$ of defecations occurring away from the upper reef crest. In total, $36.5 \%$ of all sediment ingested by Ctenochaetus striatus was transported from the upper reef crest to deeper habitats. Using the estimated volume of sediment ingested by $C$. striatus from the defecation rate model revealed that each fish at Site A
A

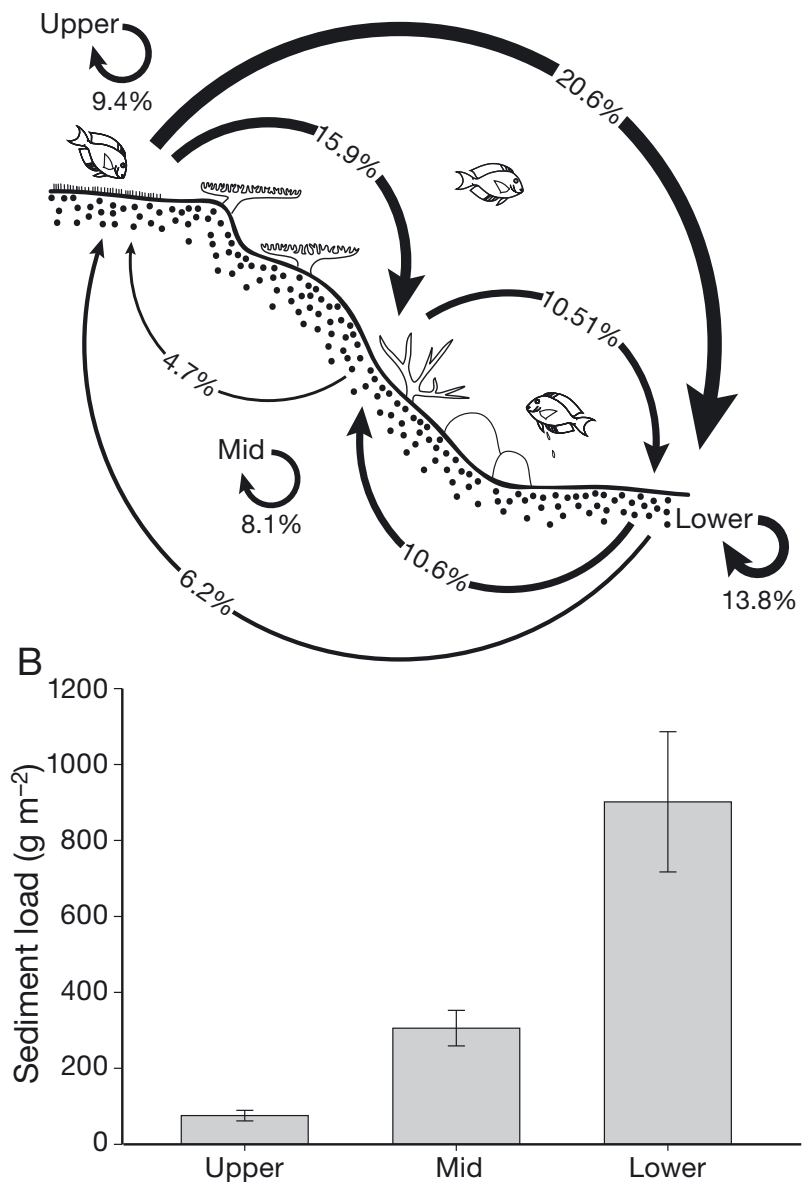

Fig. 4. Ctenochaetus striatus. (A) Sediment transport by C. striatus on the reef crest. Arrow values represent the percent of total ingested sediment that is transported between habitats (upper, mid and lower reef crest). (B) The mean benthic sediment load $\left(\mathrm{g} \mathrm{m}^{-2} \pm \mathrm{SE}\right)$ in the 3 reef crest habitats ( $\mathrm{n}=20$ for each habitat)

transported $24.3 \pm 5.3 \mathrm{~g} \mathrm{~d}^{-1}$ away from the upper reef crest compared to $9.1 \pm 2.6 \mathrm{~g} \mathrm{~d}^{-1}$ at Site B.

Ctenochaetus striatus may also act to move sediments from areas of high hydrodynamic exposure to sheltered locations, with $60.0 \%$ of defecations observed to occur in overhangs, crevices, or caves. This is likely an underestimation, as C. striatus was repeatedly observed to defecate in cryptic areas, which could only be detected after the event, by observing the faecal pellet.

The abundances of Ctenochaetus striatus at Sites A and $\mathrm{B}$ were found to be $3.2 \pm 0.5$ and $5.8 \pm 0.9$ fish $100 \mathrm{~m}^{-2}$, respectively. With this abundance, C. striatus has the potential to transport $28.6 \pm 6.2$ and $19.2 \pm$ $5.5 \mathrm{~kg} 100 \mathrm{~m}^{-2} \mathrm{yr}^{-1}$ at Sites A and B, respectively (using the defecation rate model transport estimates).

The weights of reef sediments collected using the electronic vacuum sampler did not differ between 
sites; thus, the results were pooled. The mean sediment load of the upper reef crest was $75.5 \pm 14.0 \mathrm{~g} \mathrm{~m}^{-2}$ increasing to $901.7 \pm 184.6 \mathrm{~g} \mathrm{~m}^{-2}$ at the lower crest $\left(F_{2,57}=14.97, \mathrm{p}<0.0001\right.$; Fig. $\left.4 \mathrm{~B}\right)$. Without considering sediment inputs, the feeding of Ctenochaetus striatus therefore equates to the complete removal of sediments from the upper reef crest EAM $3.8 \pm 0.8$ and $2.5 \pm 0.7$ times $\mathrm{yr}^{-1}$ at Sites A and B, respectively.

\section{DISCUSSION}

Off-reef sediment flux mediated by the lined bristletooth Ctenochaetus striatus (Acanthuridae) was quantified at Lizard Island, northern Great Barrier Reef. Although a tendency to defecate away from feeding areas has been documented for C. striatus (Krone et al. 2008), its role in biologically mediated sediment flux on coral reefs has not previously been quantified.

\section{Sediment transport and its effects}

Ctenochaetus striatus feeds primarily on the upper reef crest. Although it probably targets detritus (Purcell \& Bellwood 1993), it ingests sediments in the process. It then moves into deeper waters to defecate, depositing the sediments, often in locations sheltered from hydrodynamic exposure. Remarkably, the quantities of sediment ingested by each C. striatus $(8.8 \pm 2.4$ to $66.1 \pm 14.4 \mathrm{~g} \mathrm{fish}^{-1} \mathrm{~d}^{-1}$ ) are broadly comparable with the quantity of existing sediments reworked by even large excavating parrotfishes such as Chlorurus microrhinos and Ch. sordidus (Labridae) $(68.6 \pm 21.6 \mathrm{~g}$ and $24.1 \pm 7.4 \mathrm{~g} \mathrm{fish}^{-1} \mathrm{~d}^{-1}$, respectively; Bellwood 1996). This is particularly striking, as these parrotfishes are up to 26 times heavier than C. striatus (Choat et al. 2004). Even using the methods that provide the lowest estimates of sediment ingestion by $C$. striatus, such as the bite rate and bite volume model, the high abundances of $C$. striatus on Indo-Pacific coral reefs (Choat \& Bellwood 1985, Sluka \& Miller 2001) ensure that C. striatus remain of considerable potential importance in reef sediment dynamics.

The ecological impact of Ctenochaetus striatus is very different to that of parrotfishes. While even small Scarus spp. leave clearly visible grazing scars where the reef matrix is exposed (Bonaldo \& Bellwood 2008, 2009), C. striatus feeds in an essentially non-destructive manner, using its bristle-like teeth to sweep detritus from the EAM, simultaneously ingesting sediments (Purcell \& Bellwood 1993, Krone et al. 2008). This method of feeding is very unusual in reef fishes. Even amongst acanthurids, sweeping detritus from EAMs is unique to Ctenochaetus spp., with superficially similar
Acanthurus spp. cropping algae with blade-like teeth (Choat 1991). The only reef fishes to feed in a similar manner on coral reefs are salariin blennies (Blennidae; Wilson 2000), which have no taxonomic links with the other reef herbivores (Smith \& Wheeler 2006). Removing sediments without significant bioerosion may benefit reefs by reducing sediment-induced stress on corals without reducing carbonate accretion rates (cf. Mallela \& Perry 2007).

Furthermore, by sweeping sediments from the EAM, feeding by Ctenochaetus striatus may act to increase reef fish herbivory, a critical process on coral reefs (e.g. Bellwood et al. 2004). Experimental sediment removal from EAMs at Lizard Island resulted in 3.8-fold increases in herbivore feeding rates over short time periods (Bellwood \& Fulton 2008). The cause of this behaviour is currently unknown, but may be due to diminished accessibility or utility of resources in the EAM when sediment is present (Purcell \& Bellwood 2001). Decreased light attenuation in the EAM by reducing sediments may also provide a more nutritious prey for herbivores (e.g. Polunin \& Klumpp 1989). Regardless of the mechanism, by reducing sediment loads, C. striatus appears to increase the palatability of EAMs to grazing herbivorous reef fishes, increasing the impact of this vital functional group.

EAMs, consisting of algal turfs and associated organic and inorganic components (Wilson \& Bellwood 1997) are ubiquitous on coral reefs, and differences in their composition can have important effects on benthic communities. Sediment-free algal turfs in the EAM, for example, can promote coral settlement (DiazPulido et al. 2010). However, as the EAM traps sediments without suffering damage (Airoldi et al. 1996, Purcell 2000), there may be negative effects. Although adult coral colonies can outcompete EAMs (McCook 2001), sediment accumulation can prevent coral recruitment (Birrell et al. 2008). By reducing trapped sediment, Ctenochaetus striatus may play an important role, providing favourable settlement surfaces for sessile benthic organisms, thus increasing the potential for reefs to recover from disturbances. C. striatus may, therefore, increase reef resilience.

\section{Comparison of methods}

When considering the advantages of the 3 methods, the defecation rate and faecal pellet size approach has advantages over the other 2 models employed. This is not due to the fact that it predicts the largest effect by Ctenochaetus striatus but because the model is reliant on fewer variables than the bite rate and bite volume model and suffers from fewer sources of error. This approach is also non-destructive (no fish need be sac- 
rificed) and entirely based on data collected by the authors at the study site, rather than published values from other locations as is the case for the gut contents and throughput rate method. Furthermore, any errors accrued using the defecation rate and faecal pellet size approach tend to be conservative, as it is difficult to collect all faecal pellets intact. The volume of sediment in a faecal pellet is likely to be an underestimate, as some sediment may have been left on the reef. Likewise, the defecation rate is also likely to be an underestimate, as during faecal pellet collections C. striatus were often seen to defecate in cryptic environments in the reef (crevices and caves), which could only be detected after the event by looking for the faecal pellet. These events would have been missed by observers and video analyses. This observation may help to explain the site effect found using this method, as Site B had greater topographic complexity and more 'cryptic' defecation locations. Thus, defecation events may have been missed at Site B. The final reason we believe this approach to be conservative is that it makes no allowance for material lost (defecated) during the night. Despite the errors resulting in underestimates, this method consistently gives the highest values. Errors for the other methods may be positive or negative, making the results more complex to interpret. Given the above, subsequent analyses of the volume of sediment ingested were based on estimates derived from the defecation rate and faecal pellet size approach.

The defecation rate and faecal pellet method, although applicable here, might have limitations if applied to other taxa. The faecal pellets of Ctenochaetus striatus are relatively unusual amongst herbivores on coral reefs in that they remain consolidated for some time after defecation, allowing them to be collected. This method would, unfortunately, be impractical in studying parrotfishes, which produce rapidly dispersing clouds of faeces (Sazima et al. 2005). Nonetheless, as the defecation rate and faecal pellet size method produced estimates considerably larger than those from the other methods, one may have to take care when using estimates that rely on gut filling or throughput estimates. Based on the current study, they may considerably underestimate sediment throughput.

\section{Biologically mediated sediment flux on coral reefs}

The importance of the ecological roles played by sediments on coral reefs is gradually becoming more apparent. Where biologists have repeatedly shown the deleterious physiological effects of increased sediments on individual benthic organisms (e.g. Fabricius et al. 2007) and geologists have shown the broad-scale implications of sedimentation in controlling the development, distribution and fate of coral reefs (e.g. Blanchon \& Shaw 1995), there has been a shortage of studies that link these fields. Ecological studies, which incorporate both the biological and physical components of the ecosystem, bridge this knowledge gap and provide valuable insights into processes contributing to reef resilience.

The present study and the few other studies considering biologically mediated sediment flux on coral reefs (Bellwood 1995a,b, Krone et al. 2008) have each revealed an unexpected biological contribution to reef sediment dynamics. But these cover a small number of species over small spatial scales. Future studies must consider the interactions between sediments and reef organisms across larger spatial scales, in particular considering marine and terrigenous sedimentation gradients. Sediments play a crucial role in reef development and maintenance, but the extent to which this is due to direct impacts (smothering, light attenuation, etc.) or indirect impacts, such as mediating critical ecosystem functions (herbivory, recruitment, etc.), is, at present, unknown. Currently, sediment is generally considered harmful to coral reefs. Sediment is a ubiquitous feature of coral reefs; indeed, its presence in the EAM means that it is a significant component of the most abundant benthic substratum type on reefs (Wismer et al. 2009). That it can have a negative influence is well understood; the key question is, how much sediment is too much and what are the implications for coral reefs during a time of climate instability and change.

\section{CONCLUSIONS}

By sweeping sediments from the EAM, Ctenochaetus striatus reduces reef sediment loading while causing little damage to the algal turf. Furthermore, sediment is moved off-reef, increasing sediment in deep areas and reducing sediments in exposed areas. As a consequence, feeding by $C$. striatus may increase the attractiveness of upper reef crest EAM to reef herbivores and provide more suitable settlement surfaces for sessile benthic organisms, thus supporting reef resilience and their ability to recover from disturbances. The mass of sediment removed per individual C. striatus is comparable to even that of large parrotfishes. Given the wide distribution and high abundance of C. striatus on Indo-Pacific coral reefs, it is apparent that $C$. striatus may play a major role in reef sediment dynamics. Indeed, sediment removal may represent a key functional role on coral reefs and C. striatus a critical functional group. 
Acknowledgements. Thanks to R. M. Bonaldo, L. Dickens, A. González Cabello, S. Harte, A. Hoey, J. P. Krajewski, C. Lefèvre and the staff of the Lizard Island Research Station for field assistance and L. Airoldi, R. Dunn, A. Hoey, J. Tanner and 2 anonymous reviewers for helpful comments on the manuscript. This work is funded by the PADI Foundation, The Lizard Island Reef Research Foundation and the Australian Museum through a Lizard Island Doctoral Fellowship (C.H.R.G.) and the Australian Research Council (D.R.B.).

\section{LITERATURE CITED}

Adams LM, Cumbo VR, Takabayashi M (2009) Exposure to sediment enhances primary acquisition of Symbiodinium by asymbiotic coral larvae. Mar Ecol Prog Ser 377: $149-156$

Airoldi L (2003) The effects of sedimentation on rocky coast assemblages. Oceanogr Mar Biol Annu Rev 41:161-236

> Airoldi L, Fabiano M, Cinelli F (1996) Sediment deposition and movement over a turf assemblage in a shallow rocky coastal area of the Ligurian Sea. Mar Ecol Prog Ser 133: 241-251

Airoldi L, Balata D, Beck MW (2008) The gray zone: relationships between habitat loss and marine diversity and their applications in conservation. J Exp Mar Biol Ecol 366:8-15

Anthony KRN, Fabricius KE (2000) Shifting roles of heterotrophy and autotrophy in coral energetics under varying turbidity. J Exp Mar Biol Ecol 252:221-253

Bak RPM (1994) Sea urchin bioerosion on coral reefs: place in the carbonate budget and relevant variables. Coral Reefs 13:99-103

Bellwood DR (1995a) Direct estimate of bioerosion by two parrotfish species, Chlorurus gibbus and C. sordidus, on the Great Barrier Reef, Australia. Mar Biol 121:419-429

Bellwood DR (1995b) Carbonate transport and within-reef patterns of bioerosion and sediment release by parrotfishes (family Scaridae) on the Great Barrier Reef. Mar Ecol Prog Ser 117:127-136

Bellwood DR (1996) Production and reworking of sediment by parrotfishes (family Scaridae) on the Great Barrier Reef, Australia. Mar Biol 125:795-800

Bellwood DR, Fulton CJ (2008) Sediment-mediated suppression of herbivory on coral reefs: Decreasing resilience to rising sea-levels and climate change? Limnol Oceanogr 53:2695-2701

Bellwood DR, Hughes TP, Folke C, Nyström M (2004) Confronting the coral reef crisis. Nature 429:827-833

Birrell CL, McCook LJ, Willis BL, Diaz-Pulido GA (2008) Effects of benthic algae on the replenishment of corals and the implications for the resilience of coral reefs. Oceanogr Mar Biol Annu Rev 46:25-63

Blanchon P, Shaw J (1995) Reef drowning during the last deglaciation: evidence for catastrophic sea-level rise and ice-sheet collapse. Geology 23:4-8

Bonaldo RM, Bellwood DR (2008) Size-dependent variation in the functional role of the parrotfish Scarus rivulatus on the Great Barrier Reef, Australia. Mar Ecol Prog Ser 360: 237-244

Bonaldo RM, Bellwood DR (2009) Dynamics of parrotfish grazing scars. Mar Biol 156:771-777

Bruggemann JH, van Kessel AM, van Rooij JM, Breeman AM (1996) Bioerosion and sediment ingestion by the Caribbean parrotfish Scarus vetula and Sparisoma viride: implications of fish size, feeding mode and habitat use. Mar Ecol Prog Ser 134:59-71

Carreiro-Silva M, McClanahan TR (2001) Echinoid bioerosion and herbivory on Kenyan coral reefs: the role of protection from fishing. J Exp Mar Biol Ecol 262:133-153

Choat JH (1991) The biology of herbivorous fishes on coral reefs. In: Sale P (ed) The ecology of fishes on coral reefs. Academic Press, San Diego, CA, p 120-155

Choat JH, Bellwood DR (1985) Interactions amongst herbivorous fishes on coral reefs: influence of spatial variation. Mar Biol 89:221-234

Choat JH, Robbins WD, Clements KD (2004) The trophic status of herbivorous fishes on coral reefs. II. Food processing modes and trophodynamics. Mar Biol 145:445-454

> Diaz-Pulido G, Harii S, McCook LJ, Hoegh-Guldberg O (2010) The impact of benthic algae on the settlement of a reef-building coral. Coral Reefs 29:203-208

Fabricius KE (2005) Effects of terrestrial runoff on the ecology of corals and coral reefs: review and synthesis. Mar Pollut Bull 50:125-146

Fabricius KE, Golbuu Y, Victor S (2007) Selective mortality in coastal reef organisms from an acute sedimentation event. Coral Reefs 26:69

Fulton CJ, Bellwood DR, Wainwright PC (2001) The relationship between swimming ability and habitat use in wrasses (Labridae). Mar Biol 139:25-33

Krone R, Bshary R, Paster M, Eisinger M, van Treeck P, Schumacher H (2008) Defecation behaviour of the lined bristletooth surgeonfish Ctenochaetus striatus (Acanthuridae). Coral Reefs 27:619-622

Larcombe P, Woolfe KJ (1999) Increased sediment supply to the Great Barrier Reef will not increase sediment accumulation at most coral reefs. Coral Reefs 18:163-169

Lipps JH (1988) Predation of foraminifera by coral reef fish: taphonomic and evolutionary implications. Palaios 3: 315-326

Mallela J, Perry CT (2007) Calcium carbonate budgets for two coral reefs affected by different terrestrial runoff regimes, Rio Bueno, Jamaica. Coral Reefs 26:129-149

- Marnane MJ, Bellwood DR (2002) Diet and nocturnal foraging in cardinalfishes (Apogonidae) at One Tree Reef, Great Barrier Reef, Australia. Mar Ecol Prog Ser 231: 261-268

McCook LJ (2001) Competition between corals and algal turfs along a gradient of terrestrial influence in the nearshore central Great Barrier Reef. Coral Reefs 19:419-425

McCulloch M, Fallon S, Wyndham T, Hendy E, Lough J, Barnes D (2003) Coral record of increased sediment flux to the inner Great Barrier Reef since European settlement. Nature 421:727-730

- Neil DT, Orpin AR, Ridd PV, Yu B (2002) Sediment yield and impacts from river catchments to the Great Barrier Reef lagoon. Mar Freshw Res 53:733-752

Perry CT, Spencer T, Kench PS (2008) Carbonate budgets and reef production states: a geomorphic perspective on the ecological phase-shift concept. Coral Reefs 27: 853-866

Polunin NVC, Klumpp DW (1989) Ecological correlates of foraging periodicity in herbivorous reef fishes of the Coral Sea. J Exp Mar Biol Ecol 126:1-20

Polunin NVC, Harmelin-Vivien M, Galzin R (1995) Contrasts in algal food processing among five herbivorous coral-reef fishes. J Fish Biol 47:455-465

Purcell SW (1996) A direct method for assessing sediment load in epilithic algal communities. Coral Reefs 15: 211-213

Purcell SW (2000) Association of epilithic algae with sediment distribution on a windward reef in the northern Great Barrier Reef, Australia. Bull Mar Sci 66:199-214

Purcell SW, Bellwood DR (1993) A functional analysis of food 
procurement in two surgeonfish species, Acanthurus nigrofuscus and Ctenochaetus striatus (Acanthuridae). Environ Biol Fishes 37:139-159

Purcell SW, Bellwood DR (2001) Spatial patterns of epilithic algal and detritus resources on a windward coral reef. Coral Reefs 20:117-125

Rogers CS (1983) Sublethal and lethal effects of sediments applied to common Caribbean reef corals in the field. Mar Pollut Bull 14:378-382

Sazima C, Bonaldo RM, Krajewski JP, Sazima I (2005) The Noronha wrasse: a 'jack-of-all-trades' follower. Aqua J Ichthyol Aquat Biol 9:97-108

Scoffin TP (1992) Taphonomy of coral reefs: a review. Coral Reefs 11:57-77

Sluka RD, Miller MW (2001) Herbivorous fish assemblages and herbivory pressure on Laamu Atoll, Republic of Maldives. Coral Reefs 20:255-262

Smith WL, Wheeler WC (2006) Venom evolution widespread

Editorial responsibility: Laura Airoldi,

Ravenna, Italy in fishes: a phylogenetics road map for the bioprospecting of piscine venoms. J Hered 97:206-217

Trip EL, Choat JH, Wilson DT, Robertson DR (2008) Interoceanic analysis of demographic variation in a widely distributed Indo-Pacific coral reef fish. Mar Ecol Prog Ser 373:97-109

Wilson SK (2000) Trophic status and feeding selectivity of blennies (Blennidae: Salariini). Mar Biol 136:431-437

> Wilson S, Bellwood DR (1997) Cryptic dietary components of territorial damselfishes (Pomacentridae, Labroidei). Mar Ecol Prog Ser 153:299-310

Wismer S, Hoey AS, Bellwood DR (2009) Cross-shelf benthic community structure on the Great Barrier Reef: relationships between macroalgal cover and herbivore biomass. Mar Ecol Prog Ser 376:45-54

Yahel R, Yahel G, Genin A (2002) Daily cycles of suspended sand at coral reefs: a biological control. Limnol Oceanogr 47:1071-1083

Submitted: May 15, 2010; Accepted: August 5, 2010 Proofs received from author(s): September 14, 2010 